\title{
Meta-Heuristic Algorithm Optimized Fuzzy PID Controlled AGC of Three Area Power System
}

\author{
B. Arun, B. V. Manikandan, K. Premkumar
}

\begin{abstract}
The problem of automatic generation control (AGC) is a major concern in power utilities; it plays a major role of the complicated structure and dimension of the multi-area systems. Automatic Generation Control's main intention in the multi-area system is to maintain the frequency of each control area and remain the tie-line power flows within the many defined tolerance limits by modifying the Automatic Generation Control generators' actual power outputs to accommodate the changing load requirements. Frequency control is accomplished through the primary control mechanism or the governor control mechanism. But the Area Control Error (ACE) always present in the system. The secondary controllers are surmounting this ACE to zero. The design tunes the controllers to enhance the better dynamic performance and stability of these eccentric conditions. The goal of this work is to diminish area control error, settle time, under-shoots and over-shoots of frequency divergence and net interchange tie-line error. Generally the gain values of the PID Control parameters obtain by tribulation and error technique and it need additional computation time. To reduce this obscurity of tuning of PID gains Evolutionary algorithm approach can be habituated to optimize the PID gains. Fuzzy - PID have been employed with different objective to enhance the efficient optimal solutions to the three area system. In this proposed study, GWO technique used to maximize Fuzzy-based PID controller's Proportional, Integral and Derivative gains in Three Area System.
\end{abstract} Particle Swarm Optimization (PSO), Grey Wolf Optimization (GWO).

\section{INTRODUCTION}

The power system components' most important goal is to ensure stable state service and efficiency and power supply eminence. The present power system is relegated into several sources like, thermal, nuclear, hydro, gas and renewable energy power stations having assorted by utility system. To keep the frequency and net schedule values in nearby control areas are the prime goal of AGC [1]. ACE is controlled by the outcome of AGC guided to zero. The significance of the control is to diminish the error value of ACE to zero under the steady state operations. A good area regulation is required to frequency deviation in a few areas of the unified system to

Revised Manuscript Received on December 30, 2019.

* Correspondence Author

*Arun B., assistant professor, Department of Electrical and Electronics Engineering, R. V. S College of Engineering, Tamil nadu, India. E-mail id: arunjibose@gmail.com

Manikandan B. V., senior professor, Department of Electrical and Electronics Engineering, Mepco Schlenk Engineering College, Tamil nadu, India. E-mail id: bvmani@mepcoeng.ac.in

Premkumar K., Associate Professor, Department of Electrical and Electronics Engineering, Rajalakshmi Engineering College, Tamil nadu, India. E-mail id: prem.kamaraj@gmail.com

(C) The Authors. Published by Blue Eyes Intelligence Engineering and Sciences Publication (BEIESP). This is an open access article under the CC BY-NC-ND license (http://creativecommons.org/licenses/by-nc-nd/4.0/)
Keywords: Area Control Error (ACE), Genetic Algorithm (GA),

adjust its generation and to restore the nominal frequency and tie-line variations. All control areas support the other control areas due to large changes of load or generation. The interconnected power system which attempts for successful operation to meet out the area control errors in terms of frequency and net interchanges. The conventional controller such as a PID controller for the AGC is most popular in industries because it is very simple, facile to implement, low cost and robust. But the same controller has not an adequate performance for the system parameters and load variations and considering nonlinearity quandaries. The gains of PID controllers do not felicitously tune the system may the poor dynamic response of the system and it causes to system instability problem. Hence, the conventional controller tuning the gains of KP, KI and KD parameters via some of classical tuning methods desires in the entire set of in sequence associated with the plant performance and requisite information about the quandary [2] - [5]. By the introduction of soft computing techniques such as fuzzy logic approach for optimal tuning of PID gain parameters and gets a better efficiency and stability of the AGC quandary [6] - [9]. The algorithms suggested that include peak and undershoot oscillations, settling time, robustness and processing time compared to conventional PID controllers.

\section{LITERATURE REVIEW}

The main important goal of the power system components is to ensure safe operation, reliability and power supply quality. It is acknowledged as an Automatic Generation Control. Under stable conditions, function of AGC to mitigate the error of oscillations. If LFC does not provide sufficient damping, the oscillations will continue for a long time, causing the system to collapse [10]. The AGC problem formulation with conventional techniques for an isolated area having single source such as thermal power plant is highlighted in [11]. The result of single time delay on controller response for the single area is presented and the AGC problem with diverse sources of generation in single area is discussed in [12]. The hydro power plant with different governor responses at different load conditions as well as for dump load in an isolated area is presented [13]. The solution to AGC problem in multi-area system model in each area considering the non-linearities is proposed [14], [15]. To take into account Automatic generation control for multi-area network with a different number of generators in different areas with contact delay has presented in [16]. In [17], the author examined the AGC with various turbine units The customized PID structure for LFC of thermal system model is examined in [18], [19]. In [20], the author explained a sophisticated optimal design of an AGC congruent PI Controller. 
In [21], the author has developed an incipient method for calculate the robustness of GA-simulated annealing maximization through culls a function such as fitness value in straight depends on transient quality uniqueness homogeneous to settling time, undershooting and over-shooting

Methods for optimizing genetic algorithms are much simpler, require less computational complexity, and plant other finest gain values than the genetic algorithm, particularly used in PID controllers. In [22], the author has investigated the two area reheat thermal systems using $A B C$ with different cost functions of IAE, ISE, and ITSE and compares the results with each other. The hybrid power generation system using modified particle swarm optimization techniques has designed in [23]. The tuning method of the PI controller in load frequency control utilizing genetic algorithms to damping the oscillations of the system has described in [24]. The appliance of fuzzy method in a LFC utilizing the fuzzy gain value of PI controllers has presented in [25] - [27]. In [28], the author has suggested that the AGC of the multi-area system is scheduled using the Fuzzy tuned PI. Fuzzy tuned integral controller is designed for solve the Automatic Generation Control problems and a hybrid GA-fuzzy controller is anticipated for thermal power plant multi area power system model in [29] - [31].

\section{MODELING OF AGC COMPONENTS}

When precondition of relative frequency ordinance in the generating system requires managing the turbine speed by means of governor model. In IEEE proposed the monetary standard of proper mathematical of the components of the AGC are advanced of incorporate in turbine, governor, generator and load model. In this chapter allows a concise analysis of the mathematical model of the speed governor, turbine, generator, and load of the power generating systems.

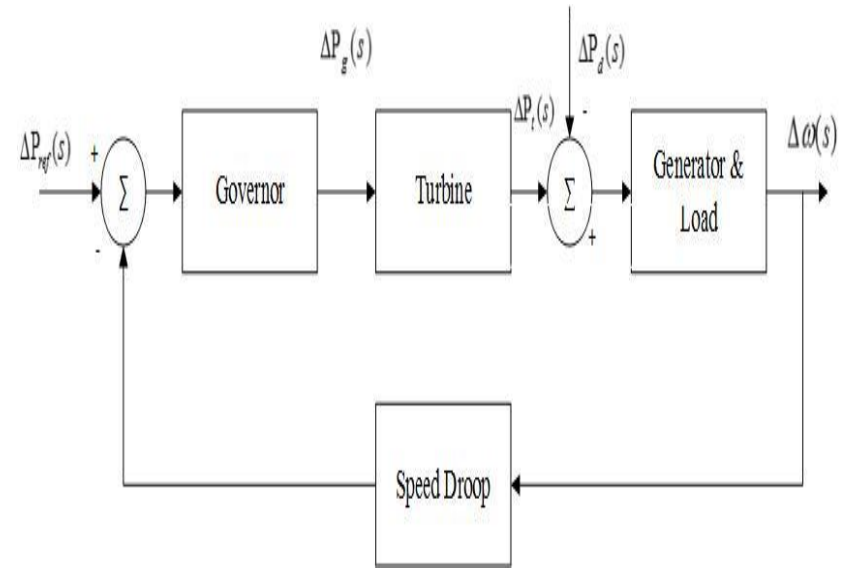

Fig.1. Block diagram of speed governing unit

$\frac{\Delta \mathrm{P} t}{\Delta \mathrm{Pg}}=\frac{\mathrm{Kg}}{1+s \mathrm{~T} g}$

$\Delta \mathrm{P}_{t}$ - incremental transmutation in turbine power

$\Delta \mathrm{P}_{g}$ - incremental transmutation in turbine power

$\mathrm{K}_{g}$ - governor gain constant

$\mathrm{T}_{g}$ - governor time constant

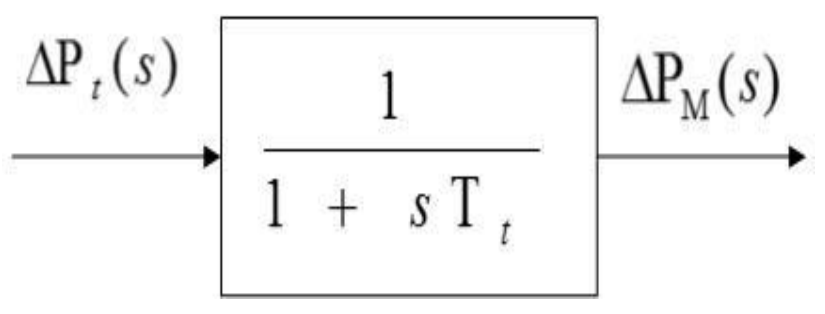

Fig.2. Non heat turbine model

$\frac{\Delta \mathrm{P} m}{\Delta \mathrm{P} t}=\frac{\mathrm{K} t}{1+s \mathrm{~T} t}$

$\Delta \mathrm{Pm}$ - incremental transmutation in valve/gate position

$\Delta \mathrm{Pt}$ - incremental transmutation in turbine power

$\mathrm{K} t$ - gain constant

$\mathrm{T} t$ - time constant

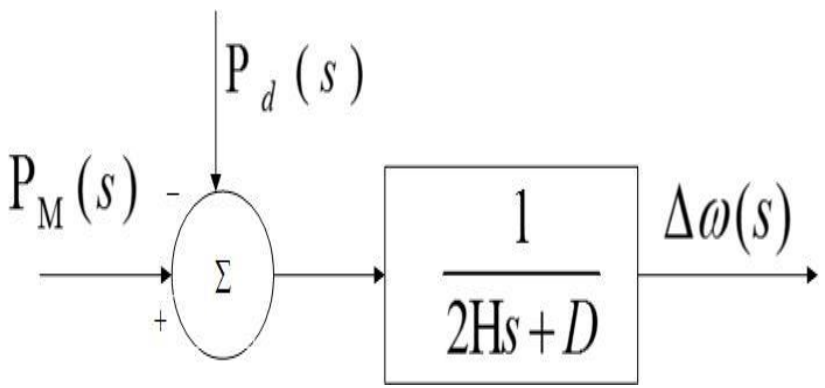

Fig.3. Generator and load model

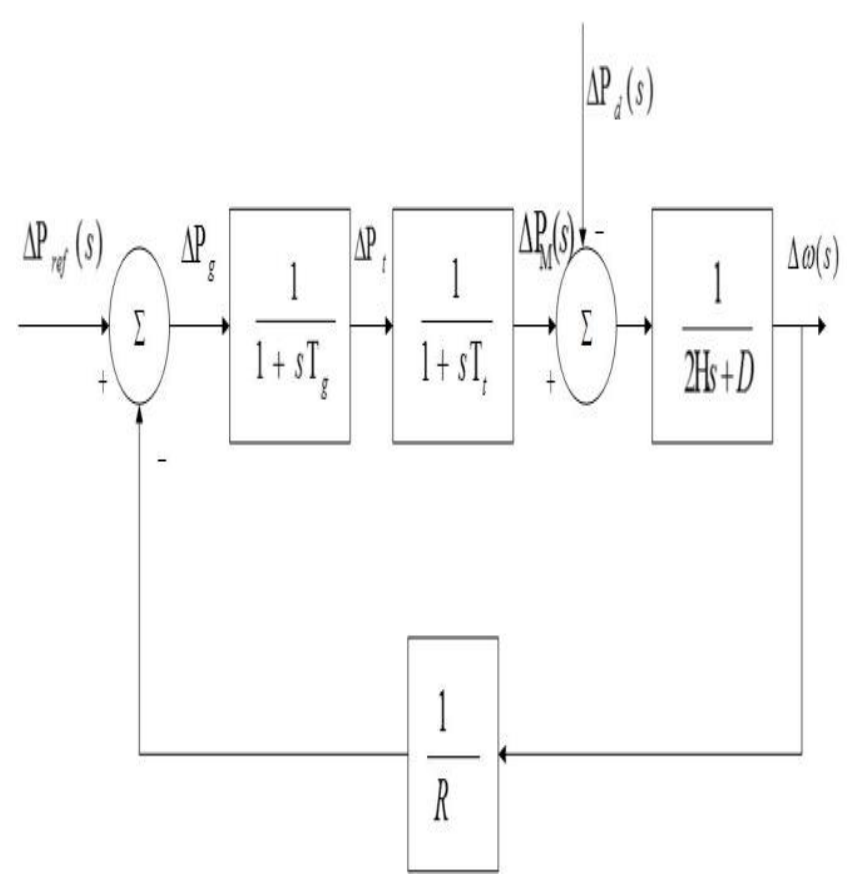

Fig.4. Single area model 


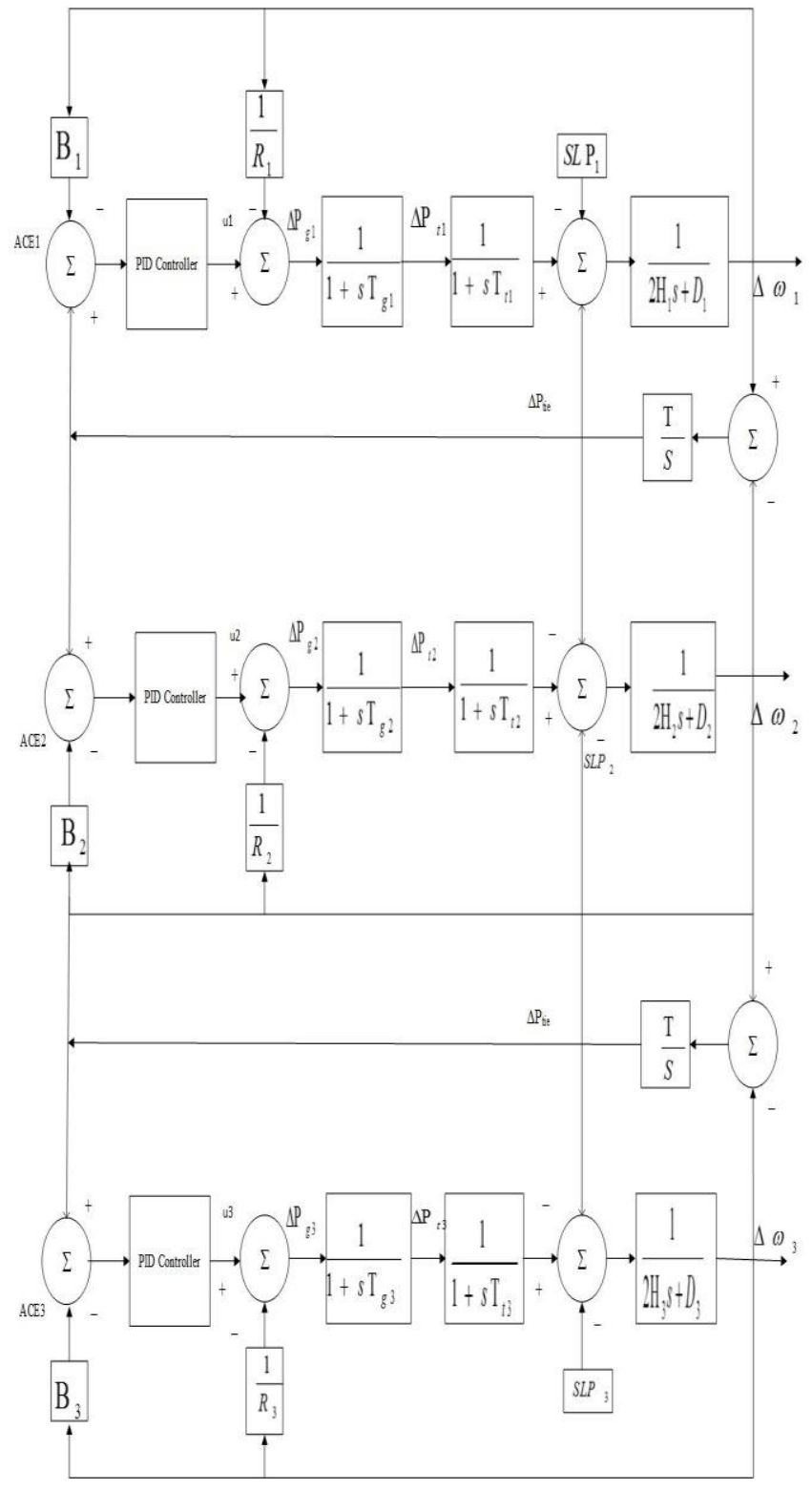

Fig.5. Three area system model

$\mathrm{ACE}_{i}=\sum_{j=1}^{n} \Delta \mathrm{P}_{i j}+\mathrm{B}_{i} \Delta \omega$

The frequency bias $\mathrm{B}_{i}$ finds the total number of connections between the neighbouring control areas. The successful operation is achieved in that area is selection of bias factor is very important about the areas.

Therefore $\mathrm{B}_{i}=\frac{1}{\mathfrak{R}_{i}}+D_{i}$; The ACE of three area system is given by the equation

$$
\begin{aligned}
& \mathrm{ACE}_{1}=\Delta \mathrm{P}_{12}+\Delta \mathrm{P}_{13}+\mathrm{B}_{1} \Delta \omega_{1} \\
& \mathrm{ACE}_{2}=\Delta \mathrm{P}_{21}+\Delta \mathrm{P}_{23}+\mathrm{B}_{2} \Delta \omega_{2} \\
& \mathrm{ACE}_{3}=\Delta \mathrm{P}_{31}+\Delta \mathrm{P}_{32}+\mathrm{B}_{3} \Delta \omega_{3}
\end{aligned}
$$

The three-area model of the AGC system is designed in simulink in view AGC components. In this thesis is executed in three-area system, while the governor will concern about the replication of both synchronous generator and tie-line potency. Since the load varies, the real power of the generating system additionally varies so real power is not able to be generated over long time intervals. The difference of control of frequency is predicated on the on the whole system of authentic power balance to AGC. Corresponding to Fig. 5, Where $B_{1}, B_{2}$ and $B_{3}$ are the bias specifications , the control outputs are $u_{1}, u_{2}$ and $u_{3}, R_{1}, R_{2}$ and $R_{3}$ are speed regulation in p.u Hz, $\mathrm{T}_{g 1}, \mathrm{~T}_{g 2}$ and $\mathrm{T}_{g 3}$ are generator constants in seconds, $\Delta \mathrm{P}_{g 1}, \Delta \mathrm{P}_{g 2}$ and $\Delta \mathrm{P}_{g 3}$ are the generator power in p.u, $\mathrm{T}_{t 1}, \mathrm{~T}_{t 2}$ and $\mathrm{T}_{t 3}$ are the turbine constants in seconds, $\Delta \mathrm{P}_{t 1}, \Delta \mathrm{P}_{t 2}$ and $\Delta \mathrm{P}_{t 3}$ are the deviation in turbine powers, $S L \mathrm{P}_{1}, S L \mathrm{P}_{2}$ and $S L \mathrm{P}_{3}$ are step load perturbations in area $1-2$ in p.u , $\Delta \omega_{1}, \Delta \omega_{2}$ and $\Delta \omega_{3}$ are frequency deviations in $\mathrm{Hz}$.

\section{FUZZY PID CONTROLLER}

The regulation of load frequency refers only to little and slow load disruption variations. By using fuzzy gain scheduling scheme, the proper optimal gain values are immediately scheduled to the controller on the occurrence of any load perturbation. Fuzzy principles and logic are used to evaluate the controller gain in line with the disruption of load.[32] - [34] As input signals, Fuzzy uses error(k1) and error derivative (k2).The Proportional, Integral and Derivative gain parameters are individually adapted to these two inputs with each input having three triangular membership functions of fuzzy gain scheduling scheme.

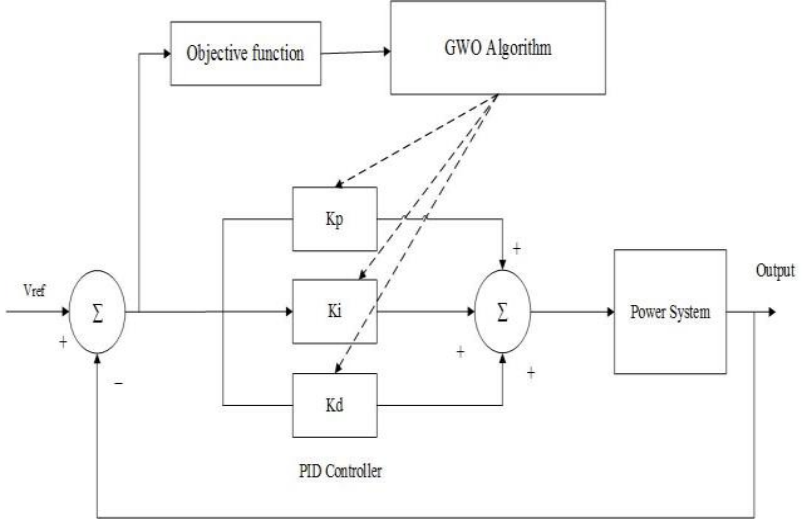

Fig.6. GWO-based PID Controller block diagram

\section{GREY WOLF OPTIMIZATION}

Among the recent meta-heuristic approach, GWO algorithm used to discover the PID controller gains and optimal values are given to the three-area PID controller [35].The implementation of GWO based PID controller as shown in Fig.6. Grey Wolf Optimization provides satisfactory damping performance under load demand and step disturbances in multi area system 


\section{RESULT AND DISCUSSION}

Case 1: In this operating condition, $\triangle \mathrm{PL} 1$ is kept at $0.4 \mathrm{p} . \mathrm{u}$ in area $1, \Delta$ PL2 is kept at 0.6 p.u in area 2 and $\triangle$ PL3 is kept at 0.4 p.u in area 3 of the proposed system. The GWO technique is achieved better performance for this operating condition. So, in this operating condition GWO technique tuned proportional, integral and derivative gain parameters are adapted to Fuzzy Gain Scheduling scheme. GWO based Fuzzy Gain Scheduling scheme are produced the good response. GWO technique and Fuzzy Gain scheduling response to GA and PSO techniques were contrasted in this situation. From Figures 13 - 16, it is understood that the Fuzzy Gain Scheduling (FGS) scheme gets slightly better transient response than the GA and PSO techniques.

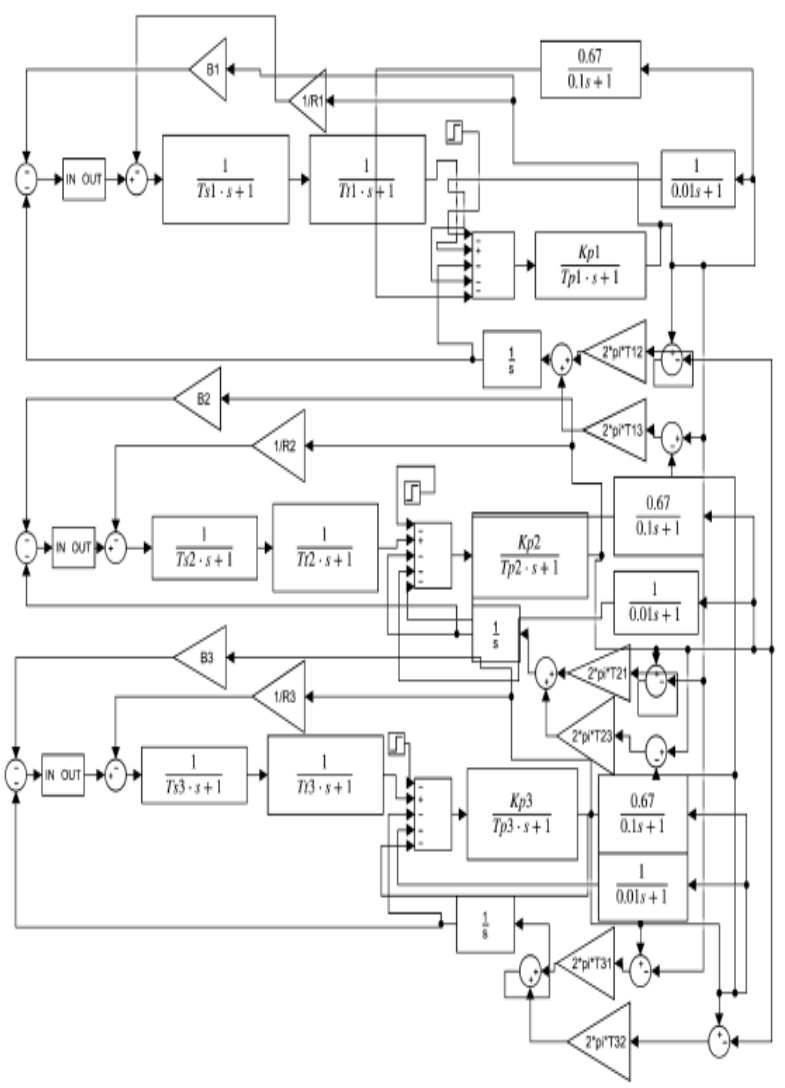

Fig.7. Overall simulink model of grey wolf optimized fuzzy PID controlled three area system

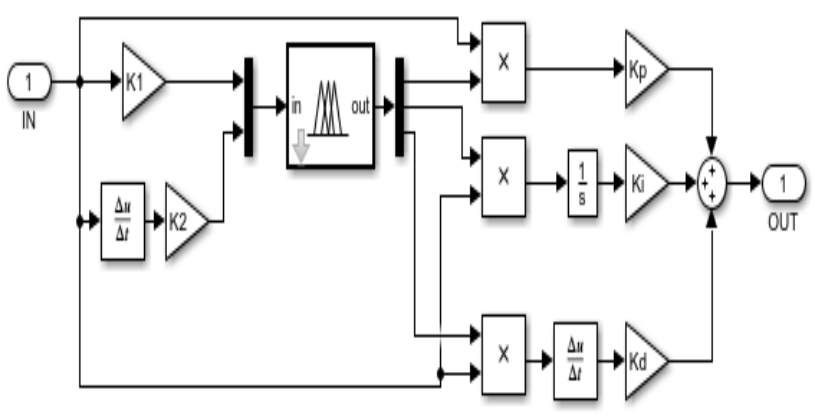

Fig.8. Fuzzy PID Controller simulink design

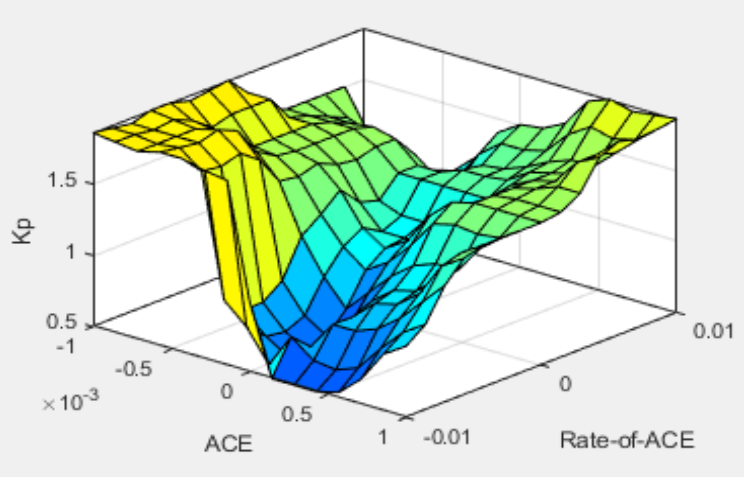

Fig.9. Rule surface for $\mathrm{Kp}$

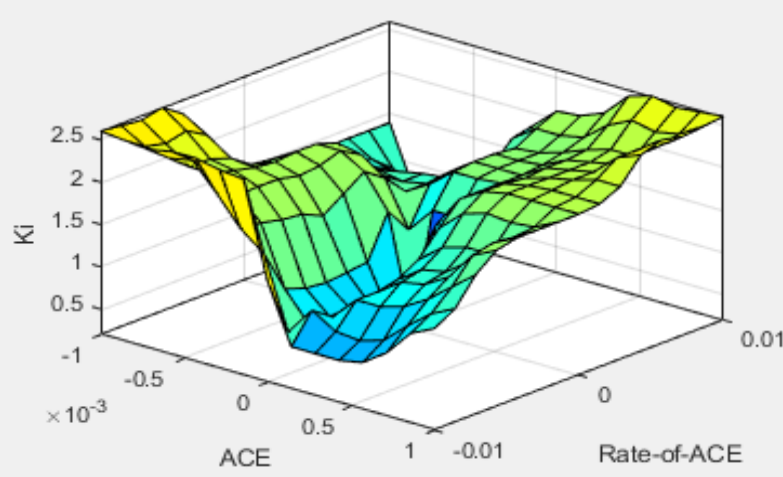

Fig. 10. Rule surface for $\mathrm{Ki}$

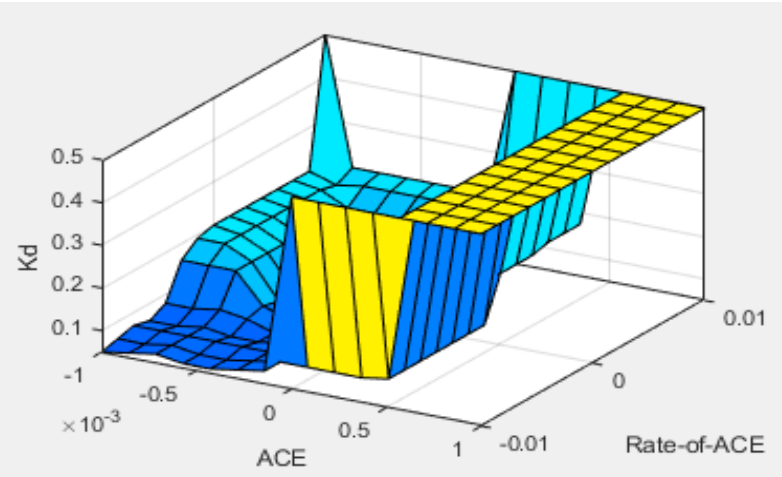

Fig. 11. Rule surface for Kd

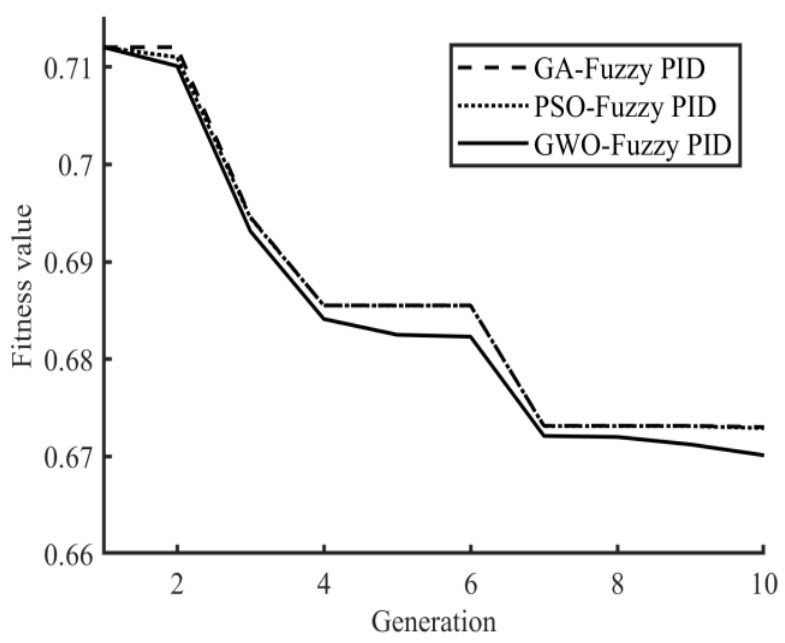

Fig. 12. Convergence graph

Published By: 
Table-I: Results of Parameter optimization

\begin{tabular}{|c|c|c|c|c|c|}
\hline \multirow{2}{*}{$\begin{array}{c}\text { Algorith } \\
\mathrm{m}\end{array}$} & \multicolumn{5}{|c|}{ Parameters } \\
\hline & K1 & $\mathrm{K} 2$ & Kp & $\mathrm{Ki}$ & $\mathrm{Kd}$ \\
\hline GA & 0.2692 & 0.5706 & 0.9092 & 0.7782 & 0.6638 \\
\hline PSO & 0.4909 & 0.5676 & 0.5074 & 0.6783 & 0.6866 \\
\hline GWO & 0.2639 & 0.6438 & 0.8903 & 0.7862 & 0.4170 \\
\hline \multirow{2}{*}{$\begin{array}{c}\text { Algorith } \\
\text { m }\end{array}$} & \multicolumn{5}{|c|}{ Parameters } \\
\hline & \multicolumn{2}{|c|}{ Best } & Worst & \multicolumn{2}{|c|}{$\mathrm{T}_{\mathrm{C}}(\mathrm{sec})$} \\
\hline GA & \multicolumn{2}{|c|}{0.67302} & .7943 & \multicolumn{2}{|c|}{365} \\
\hline PSO & \multicolumn{2}{|c|}{0.67291} & .8045 & \multicolumn{2}{|c|}{280} \\
\hline GWO & \multicolumn{2}{|c|}{0.67012} & .8701 & \multicolumn{2}{|c|}{270} \\
\hline
\end{tabular}
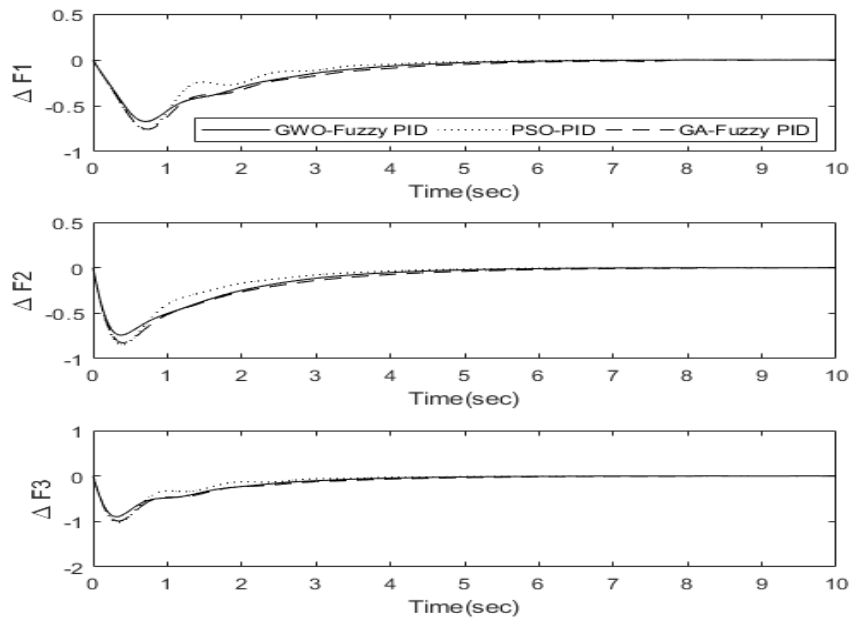

Fig.13 Frequency difference in area $1-3$
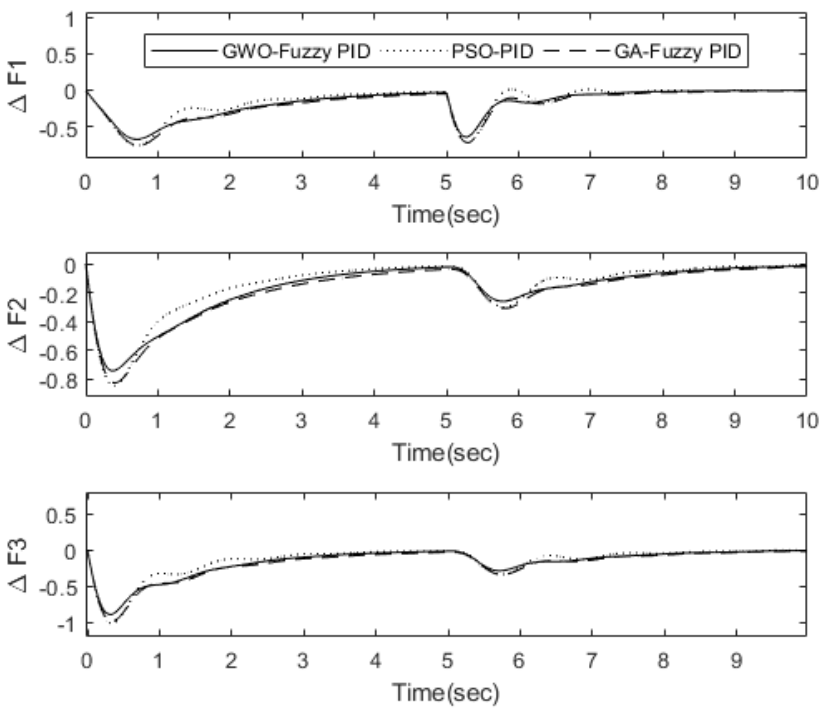

Fig. 14. Deviation in frequency for load change in area-1

2: In this operating condition, $\triangle \mathrm{PL} 1$ is vary from $0.4 \mathrm{pu}$ to $0.6 \mathrm{pu}$ in area $1, \Delta \mathrm{PL} 2$ is kept at $0.6 \mathrm{p}$.u in area 2 and $\triangle \mathrm{PL} 3$ is kept at 0.4 p.u in area 3 of load frequency control in three area power system. GWO based Fuzzy Gain Scheduling scheme response is quickly settled compared to GA and PSO techniques.
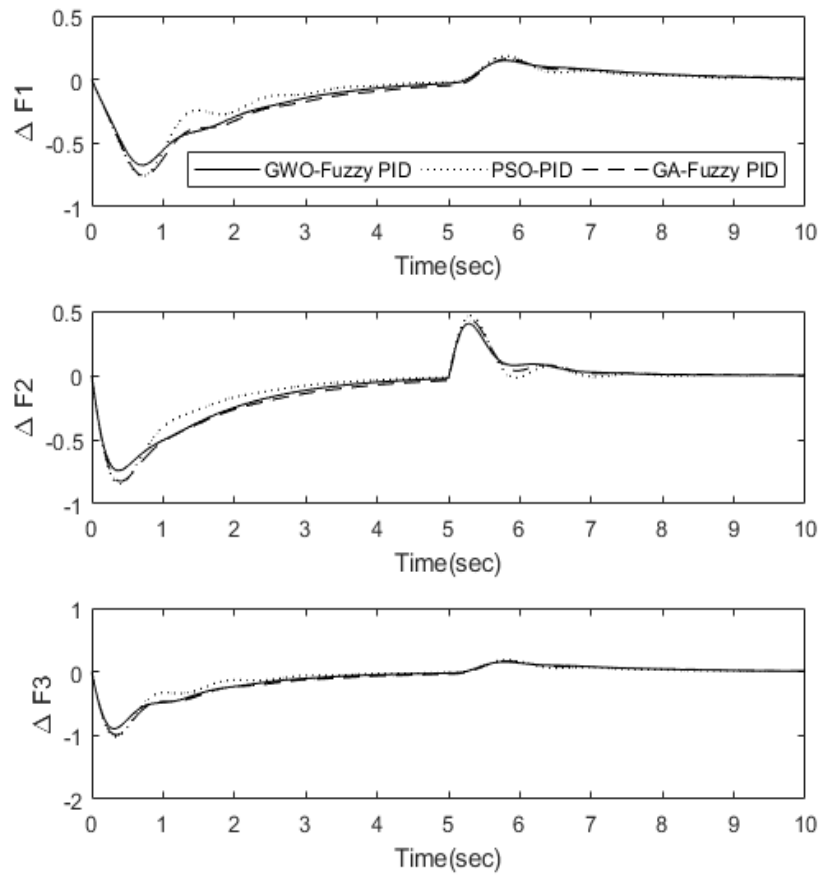

Fig.15. Deviation in frequency for change in area-2
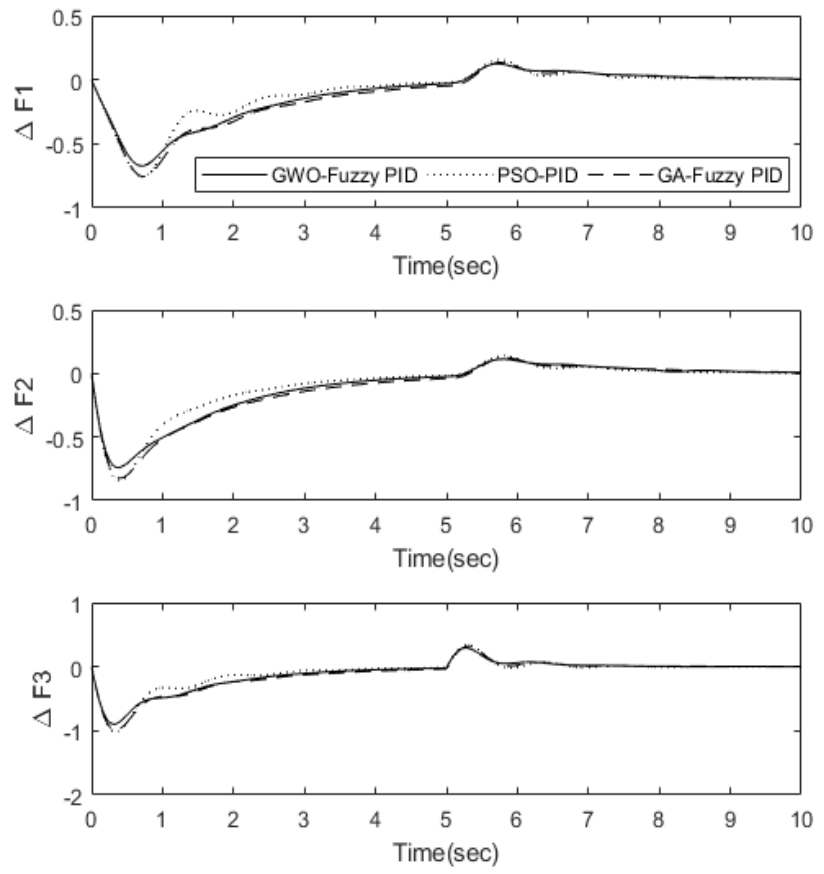

Fig.16. Deviation in frequency for load change in area-3

Case 3: In this operating condition, $\triangle \mathrm{PL} 1$ is kept at $0.4 \mathrm{pu}$ in area $1, \Delta \mathrm{PL} 2$ is change from $0.6 \mathrm{pu}$ to $0.8 \mathrm{pu}$ in area 2 and $\triangle \mathrm{PL} 3$ is kept at 0.4 p.u in area 3. GWO based Fuzzy Gain Scheduling scheme response have better performance compared to GA and PSO techniques.

Case 4: In this operating condition, $\triangle \mathrm{PL} 1$ is kept at $0.2 \mathrm{pu}$ in area $1, \Delta \mathrm{PL} 2$ is kept at $0.6 \mathrm{pu}$ in area 2 and $\triangle \mathrm{PL} 3$ is change from $0.8 \mathrm{pu}$ to $0.5 \mathrm{pu}$ in area 3. GWO based Fuzzy Gain Scheduling scheme response is quickly settled compared to GA and PSO techniques

Published By:

Blue Eyes Intelligence Engineering \& Sciences Publication 


\section{A. Sensitivity Analysis}

Sensitivity analysis is done through adjusting parameters like generator constant and turbine constant in between $+50 \%$ to $-50 \%$ from their nominal values. From Fig. 17 - 18, that the system performances merely constant for the system under study when the parameters are altered by $\pm 50 \%$.
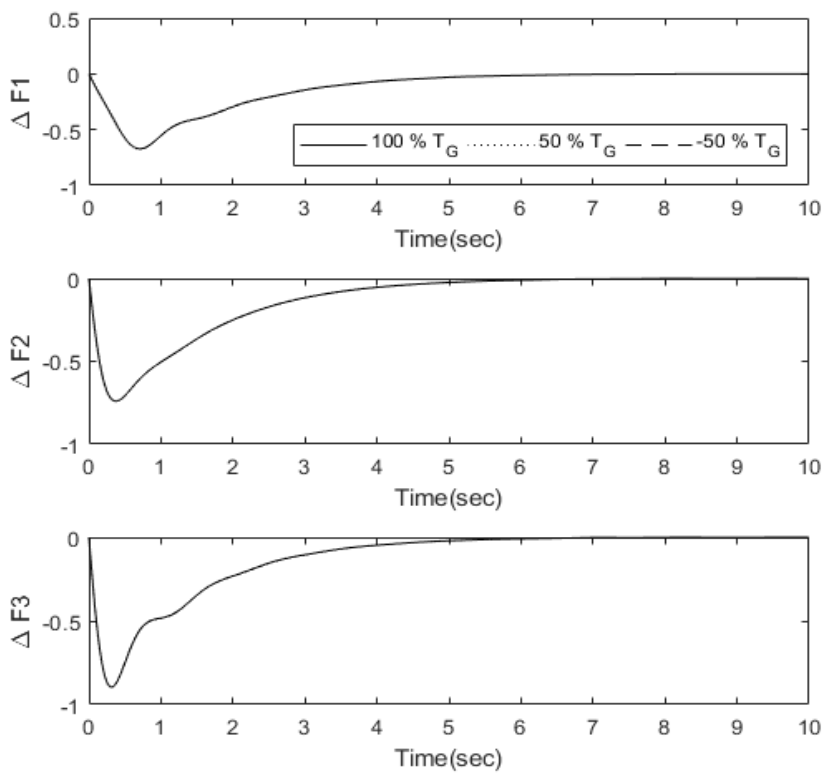

Fig.17. Sensitivity analysis for case 1 settings with TG= $100 \%, T G=50 \%$ and $T G=-50 \%$
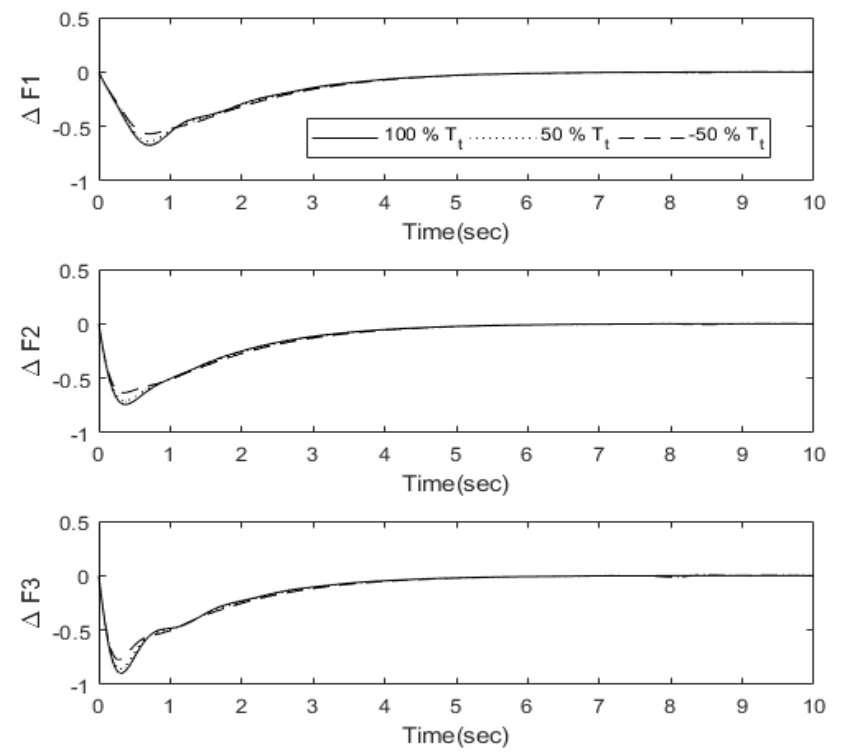

Fig.18. Sensitivity analysis for case 1 settings with $\mathbf{T t}=$ $100 \%, \mathrm{Tt}=50 \%$ and $\mathrm{Tt}=-50 \%$

\section{CONCLUSION}

In this proposed work, GWO technique used to optimize the gain of Fuzzy based PID controller in three area System. The effective ability of the GA, PSO and GWO optimized Fuzzy PID controllers was compared. This investigation of GWO optimized Fuzzy PID controller presents a superior effective ability than GA and PSO in terms of a smaller amount of undershoot, settling time, overshoot and deviation in frequency and net power variations after a perturbation of the load stage. Robustness is also achieved by means of varying system parameters to $\pm 50 \%$ to their nominal values i.e.
Generator time constant and Turbine constant and achieving dynamic system responses within tolerable limits.

\section{REFERENCES}

1. Shayeghi et al. (2009), Application of Particle Swarm Optimization technique for GEP in restructured power systems, Energy Conversion and Management, 50(1), pages.2127-2135.

2. Premkumar et al. (2019), Fuzzy Anti-Windup PID Controlled Induction Motor, International Journal of Engineering and Advanced Technology, 9,1, pages.184-189.

3. Shashi et al. (2013), A literature survey on Load Frequency Control for conventional and distribution generation power systems, Renewable and Sustainable Energy Reviews, 25, pages.318-334.

4. K Premkumar et al. (2018), Stability and Performance Analysis of ANFIS Tuned PID Based Speed Controller for Brushless DC Motor, Current Signal Transduction Therapy, 13, 1, pages.19-30.

5. Jiang et al. (2012), Delay dependent stability for load frequency control with constant and time-varying delays, IEEE Transactions on Power Systems, 27, 2, pages.932-941.

6. Premkumar, Kamaraj et al. (2018), Antlion Algorithm Optimized Fuzzy PID Supervised On-line Recurrent Fuzzy Neural Network Based Controller for Brushless DC Motor, Electric Power Components and Systems, 45, 20, pages.2304-2317.

7. Singh et al. (2012), Load frequency control of a realistic power system with multi-source power generation, International Journal of Electrical Power and Energy Systems, 42, 1, pages.426-433.

8. K Premkumar et al. (2015), Fuzzy PID supervised online ANFIS based speed controller for brushless dc motor, Neurocomputing, 157, pages.76-90.

9. Doolla et al. (2006), Load frequency control of an isolated small-hydropower plant with reduced dumped load, IEEE Transactions on Power Systems, 21, 4, pages.1912-1919.

10. K Premkumar et al. (2015), Online Fuzzy Supervised Learning of Radial Basis Function Neural Network Based Speed Controller for Brushless DC

11. Malik ae al. 1998, A load frequency control algorithm based on a generalized approach, IEEE Transactions on Power Systems, 3, 2, pages.375-382.

12. K Premkumar et al. (2018), Novel bacterial foraging-based ANFIS for speed control of matrix converter-fed industrial BLDC motors operated under low speed and high torque, Neural Computing and Applications, 29, 12, pages.1411-1434.

13. Yang et al. (1998), Decentralized load-frequency controller design based on structured singular values, IEE Proc on Generation, Transmission and Distribution, 145, 1, pages.07-14.

14. Thamizhselvan T et al. (2017), Maximum power point tracking algorithm for photovoltaic system using supervised online coactive neuro fuzzy inference system, Journal of Electrical Engineering, 17, 1, pages. 270-286

15. Alrifai et al. (2011), Decentralized Load Frequency Control for a multi-area interconnected power system, Electrical Power and Energy Systems, 33, 2, pages.198-209. Motor, Lecture Notes in Electrical Engineering, 326, pages.1397-1405.

16. M John Prabu et al. (2016), Fuzzy supervised online coactive neuro-fuzzy inference system-based rotor position control of brushless DC motor, IET Power Electronics, 9, 11, pages.2229 - 2239.

17. Dong et al. (2012), A robust decentralized load frequency control for interconnected power systems, ISA Transaction, 51, 3, pages.410-419. K

18. Premkumar et al. (2015), GA-PSO optimized online ANFIS based speed controller for Brushless DC motor, Journal of Intelligent \& Fuzzy Systems, 28, 6, pages.2839-2850.

19. Naimul et al. (2012), Sub-optimal Automatic Generation Control of interconnected power system using constrained feedback control strategy, International Journal of Electrical Power \& Energy Systems, 43, 1, pages.295-303.

20. K. Premkumar et al. (2016), Bat algorithm optimized fuzzy PD based speed controller for brushless direct current motor, Engineering Science and Technology, an International Journal, 19, 2, pages.818-840.

21. Farahani et al. (2012), PID controller adjustment using chaotic optimization algorithm for multi-area load frequency control, IET Control Theory Applications, 6, 13, pages.1984-1992.

Published By:

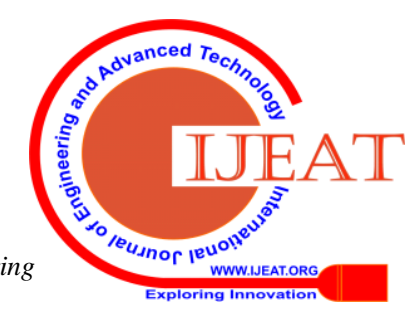


22. Alice Hepzibah, A et al. (2019), ANFIS current-voltage controlled MPPT algorithm for solar powered brushless DC motor based water pump, Electrical Engineering, https://doi.org/10.1007/s00202-019-00885-8.

23. Iracleous et al. (2005), A multi-task Automatic Generation Control for power regulation, Electric Power Systems Research, 73, 1, pages.275-285.

24. K Premkumar et al. (2013), Adaptive fuzzy logic speed controller for brushless DC motor, International Conference on Power, Energy and Control, pages.290-295.

25. Ghoshal (2004), Application of GNGA-SA based fuzzy AGC of a multi-area thermal generating system, Electric Power Systems Research, 70, 1, pages.115-127.

26. K Premkumar et al. (2015), Speed control of Brushless DC motor using bat algorithm optimized Adaptive Neuro-Fuzzy Inference System, Applied Soft Computing, 32, pages.403-419.

27. Haluk Gozde et al. (2012), Comparative performance analysis Ant Bee Colony algorithm in AGC for interconnected reheat thermal power system, Electrical Power and Energy Systems, 42 , 1, pages.167-178.

28. Wang et al. (2009), Multi-criteria design of hybrid power generation systems based on a modified particle swarm optimization algorithm, IEEE Transactions on Energy Conversion, 24, 1, pages.106-117.

29. K Premkumar et al. (2014), Adaptive Neuro-Fuzzy Inference System based speed controller for brushless DC motor, Neurocomputing, 138, pages.260-270.

30. Bomfim et al. (2000), Simultaneous tuning of power system damping controllers using genetic algorithms, IEEE Transactions on Power Systems, 15, 1, pages.163-169.

31. Ertug Rul Cam et al. (2005), Load frequency control in two-area power systems using fuzzy logic controller, Journal of Energy Conversation and Management, 46, 2, pages.233-243.

32. Chang et al. (1998), Load frequency control using GA based fuzzy gain scheduling of PI controllers, Electric Machines and Power Systems, 26, 1, pages.39-52.

33. Shyam D et al. (2019), Symmetrically modified laddered H-bridge multilevel inverter with reduced configurational parameters, International Journal of Engineering and Advanced Technology, 9 ,1, pages.5525-5532.

34. Ghoshal (2005), GA-fuzzy based fast acting adaptive active power-frequency control of interconnected multiple thermal generating areas, IE(I) Journal, 85, pages.209-215.

35. Juang, et al. (2006), Load Frequency Control by hybrid evolutionary fuzzy PI controller, IEE Proc on Generation, Transmission and Distribution, 153, 2, pages.196-204.

\section{AUTHORS PROFILE}

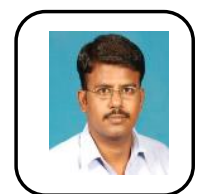

Arun B., Assistant Professor in Electrical and Electronics Engineering at R.V.S College of Engineering, Tamil nadu, India. He is familiarizing with following areas, Power frequency control in LFC, soft computing, digital controllers.

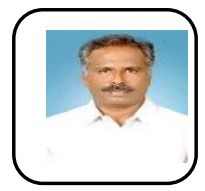

Manikandan B. V., Senior Professor Electrical and Electronics Engineering at Mepco Schlenk Engineering College, Tamil nadu, India. $\mathrm{He}$ is familiarizing with following subject areas, restructured power system, soft computing, multi area system.

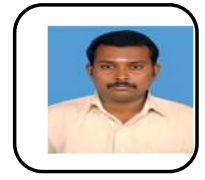

Premkumar K., Associate Professor in Electrical and Electronics Engineering at rajalakshmi engineering college, tamil nadu, india. $\mathrm{He}$ is familiarizing with following areas, soft computing, power drives, special machines, renewable energy, digital controllers. 